\title{
Health-Related Quality of Life in Patients with Type 2 Diabetes Mellitus in a Rural Area
}

Miguel Company Morales ${ }^{1,2}$, Andres Fontalba Navas ${ }^{1 *}$, Maria Filomena Rubio Jimenez ${ }^{1}$ and Jose Maria Requena Ramos ${ }^{1}$

${ }^{1}$ Northern Almeria Health Management Area, Andalusian Health Service, Spain

${ }^{2}$ Faculties of Education, Nursing and Physiotherapy, University of Almeria, Spain

\begin{abstract}
Objective: To discern health-related quality of life of patients with type 2 diabetes mellitus in a rural area of south-eastern Spain.

Methodology: A transversal descriptive study in which we analysed the link between development of the type 2 diabetes mellitus disease process and the quality of life of these patients. The SF-36 health survey was used as a tool during our study. A simple random sampling was carried out on diabetic patients $(\mathrm{N}=491)$, sample size precision $3 \%$, confidence level $95 \%$ and $15 \%$ compensation for loss resulting in a sample of $\mathrm{N}=169$. The data was analysed with SPSS 18.0 software.

Results: The type 2 diabetic population has a quality of life score of more than 50 in most of the survey's aspects. We found the lowest scores for the aspect of "Bodily Pain" (48.5). Extremely high scores were found for the aspects: "Physical Functioning" (75.5), "Role-Physical" (87.8) and "Role-Emotional" (84.7). Statistically significant differences were observed between men and women for "Bodily Pain" and "Social Functioning" $(p<0.001)$. Patients over 60 have higher scores for "Bodily Pain" ( $p<0.001)$.

Conclusions: Type 2 diabetes mellitus is associated with poor self-perceived health-related quality of life (HRQOL). The HRQOL of female diabetic patients is especially affected. Diabetic patients perceive a decrease in satisfaction with their health as their age increases.
\end{abstract}

Keywords: Quality of Life; Type 2 Diabetes Mellitus

\section{Introduction}

The main purpose of using and measuring health-related quality of life (HRQOL) is to provide a more comprehensive assessment, offering a more complete and valid evaluation of the health of an individual (or group), as well as a more precise valuation of the possible benefits and risks of medical attention.

Diabetes mellitus (DM) is a chronic metabolic disorder characterised by a common factor, hyperglycaemia, which contributes to the development of macrovascular, microvascular and neuropathic complications making DM one of the main causes of morbidity and mortality [1-7]. Diabetes is one of the most frequent chronic diseases in world and is important due to the health consequences it causes in people who suffer from it as well as disorders in their quality of life $[3,4]$.

Type 2 diabetes mellitus (DM2) is a subtype of diabetes. It is one of the most frequent pathologies in Spain with an estimated prevalence of 3 to $9 \%$ [1]. In type 2 diabetes mellitus (DM2) the pancreas creates insulin (sometimes in larger amounts than usual), but the body is not able to use it effectively. DM2 affects $90 \%-95 \%$ of people with diabetes [1]. It is the most common type of diabetes found in adults and the elderly although it can appear in children and teenagers. The probability of developing this kind of diabetes increases with age, weight gain and lack of exercise. It is generally diagnosed in people aged over 30 or 40 [5].

The Andalusian healthcare administration has, through the Council of Health and the Andalusian Health Service, in the last few years focused on frequent and serious health issues within the Planes Integrales ${ }^{3}$ action plans.

These action plans have contributed to an increase in awareness of these types of processes and an improvement in health results. The Plan Integral de Diabetes (integral action plan for diabetes) active in 2003-2007 was created to ensure better care for patients with diabetes or patients at risk of developing it. The recent assessment of the plan has proved it to be a valid and effective strategy resulting in a new plan having been created for 2009-2013 with the aim to further increase awareness, focus on the previously detected and improved areas and take advantage of technological advances in the prevention and attention to people with diabetes [6]

Prior research indicates that DM2 is a factor, which negatively affects the perception of HRQOL of patients with type 2 diabetes. The need for insulin therapy or the decrease in life expectancy due to complications caused by this pathology can negatively affect perception of HRQOL [7].

Thus, research that measures the impact of diseases on patient's HRQOL is justified. Of these, priority is given to chronic patients who must self-monitor and maintain treatment as is the case of type 2 diabetics. The HRQOL of these patients cannot be measured solely by the quantification of objective clinical parameters (like morbidity and mortality) $[8,9]$. We must also highlight that in the assessment of

${ }^{*}$ Corresponding author: Andres Fontalba Navas, Northern Almeria Health Management Area, Andalusian Health Service, Huercal-Overa, Almeria, 04600, Spain, Tel: +34619674454; E-mail: andresfontalba@gmail.com

Received April 23, 2015; Accepted June 11, 2015; Published June 16, 2015

Citation: Morales MC, Navas AF, Jimenez MFR, Ramos JMR (2015) HealthRelated Quality of Life in Patients with Type 2 Diabetes Mellitus in a Rural Area. J Diabetes Metab 6: 572. doi:10.4172/2155-6156.1000572

Copyright: (c) 2015 Morales MC, et al. This is an open-access article distributed under the terms of the Creative Commons Attribution License, which permits unrestricted use, distribution, and reproduction in any medium, provided the original author and source are credited. 
the diabetic population psychosocial aspects, not merely clinical and analytical ones, are essential in order to improve self-monitoring and treatment maintenance [10-12].

\section{Objectives of the research investigation}

To discern the health-related quality of life of patients with type 2 diabetes mellitus in a in a rural area of southeastern Spain.

\section{Materials and Methods}

Our research investigation is a transversal descriptive study in which we analysed the link between the development of the DM2 process and the quality of life of these patients.

The study was carried out at the Clinical Management Unit of Serón, which belongs to the North Almeria Health Management Area and is part of the Andalusian Health Service. Our study population comes from Valle del Almanzora, a region comprising of seven towns, which has around 8,100 inhabitants. This region of south-eastern Spain is located in the autonomous community of Andalucia and is a rural area of medium altitude mountains; its primary industries are agriculture and tertiary services.

Professional health professionals who work with the Clinical Management Unit's patient load, each of which appears in the user database, collected the data. This database is the system used in Spain to identify users of the different resources available and ensures correct allocation of health and medical services to the reference population.

The study population was obtained from cases of diabetes registered in the Diraya computer programme in 2011. The Andalusian Public Health System as an electronic medical history record uses Diraya. It registers the health information of each citizen so that it can be available whenever needed and is a management tool for the medical system.

The study time frame was between March, 2012 and February, 2014.

\section{Study sample}

A simple random sampling was carried out on the patients included in the diabetes process as of the 31st of December, $2011(\mathrm{~N}=491)$. The selected sample had 3\% precision, confidence level of $95 \%$ and $15 \%$ compensation for loss resulting in a sample of $\mathrm{N}=169$.

Patients aged over 18 and diagnosed with DM2 according to the Andalusian Health Service (who were selected in the sample) were included in the study. Patients with other types of diabetes, who had been institutionalized, with cognitive deterioration or those with a pathology, which indicated limited life expectancy were excluded. The final sample was 148 patients representative of the studied population.

\section{Instrument}

The instrument used in the study was the SF-36 Health Survey adapted to Spain by Alonso [7].

This instrument provides state of health profiles and is one of the most widely used generic scales in the assessment of clinical results. It is applicable to both the general population and to patients with a minimum age of 14 and can be used in descriptive as well as evaluation studies.

It consists of 36 items which detect both positive and negative state of health and compose eight aspects: Physical Functioning (10), Social Functioning (2), Role-Physical (4), Role-Emotional (3), Mental Health (5), Vitality (4), Bodily Pain-intensity and interference in daily work-
(2), General Health (6). A summarised description of the contents of the eight aspects is as follows:

1. Physical Functioning: measures the degree to which state of health limits physical activity such as self-care, walking, going upstairs, bending over, lifting or carrying heavy objects and any moderate or intense exertion.

2. Role-Physical: assesses the degree to which physical health interferes in work life and other daily activities, including decrease in efficiency and limitation or difficulty in carrying out activities.

3. Bodily Pain: evaluates the intensity of pain and its effect on regular work both in the home and outside.

4. General Health: provides a personal assessment of current health, future health prospects and resistance to getting sick.

5. Vitality: quantifies feelings of energy and vitality against those of tiredness or exhaustion.

6. Social Functioning: measures the degree to which physical or emotional health problems interfere in regular social life.

7. Role-Emotional: assesses the degree to which emotional problems interfere in work or other daily activities, including decrease in time dedicated to these activities and less efficiency and care at work.

8. Mental Health: measures general mental health including depression, anxiety, emotional control and control of conduct.

Response options form Likert-type scales, which evaluate intensity or frequency. The number of response options is between three and six, depending on the item.

\section{Data collection}

The eight general practitioners and seven nurses who work with the eight patient loads corresponding to the Clinical Management Unit of Serón collected the data. The patients were given the self-administered survey in the consulting room and the average time to complete it was 10 minutes.

In order to ensure uniformity in the data collection an information session was held for all researchers prior to registration of the answers and training was given for frequently asked questions.

\section{Data analysis}

The SPSS 18.0 statistical software for Windows was used for the statistical analysis. A descriptive statistical analysis of frequency, mean and standard deviation was carried out on all the codified variables. Contingency tables were made with gender and two age groups (over and under the age of 60) for each question. We consider that there is statistical significance at $\mathrm{p}<0.05 \%$.

For each of the eight aspects, the items have been codified, added to and transformed into a scale which ranges from 0 (the worst state of health for that aspect) to 100 (the best state of health).

\section{Research ethics}

This research investigation has been carried out with integrity and has at all times respected and ensured patient confidentiality and privacy of personal details. Al researchers have scrupulously respected the ethical principles that all biomedical research must ensure. The principles of non-maleficence, legality, free will and beneficence have been faithfully accomplished. This research investigation has been 
Citation: Morales MC, Navas AF, Jimenez MFR, Ramos JMR (2015) Health-Related Quality of Life in Patients with Type 2 Diabetes Mellitus in a Rural Area. J Diabetes Metab 6: 572. doi:10.4172/2155-6156.1000572

Page 3 of 5

presented to and approved by the Andalusian Health Service's ethics committee.

\section{Results}

\section{Study population characteristics}

A total of 148 people participated in the study with an average age of 71.3. The majority of participants were over 60 years of age $(74.3 \%)$. As we can observe from Table 1, women make up 52\% of the sample study with 77 participants and men make up the remaining $48 \%$ with 71 participants.

\section{Quality of life of diabetics}

The type 2 diabetic population at the Clinical Management Unit of Serón has a quality of life score of more than 50 points in most of the survey's aspects. "Bodily Pain" had the lowest score with an average of 48.5 as can be seen in Table 2 .

During analysis, extremely high scores were detected for "Physical Functioning", "Role-Physical" and "Role-Emotional".

It should be pointed out that significant differences were found between patients with DM2 and the general population in aspects such as "Bodily Pain" and "Social Functioning". Other health aspects ("RolePhysical", "Vitality" and "Role-Emotional), are level with the general population as can be seen from Table 3 .

During results analysis we observed statistically significant differences between men and women in the aspects of "Physical Functioning", "Role-Emotional" and "Mental Health" (Table 4). These differences have more significance for the "Bodily Pain" and "Social Functioning" aspects.

As can be seen in Table 5, significant differences can be observed when patients aged over 60 are compared to those under that age. The latter had higher scores in the majority of the survey's aspects. However, patients over 60 presented higher scores in "Bodily Pain",

\begin{tabular}{|c|c|c|}
\hline Participants (N) & \multicolumn{2}{|c|}{148} \\
\hline \multirow{2}{*}{ Distribution by gender } & Men & $71(48 \%)$ \\
\cline { 2 - 3 } & Women & $77(52 \%)$ \\
\hline \multirow{2}{*}{ Age } & Average & 71.3 years \\
\cline { 2 - 3 } & -60 years & $38(25.7 \%)$ \\
\cline { 2 - 3 } & +60 years & $110(74.3 \%)$ \\
\hline
\end{tabular}

Table 1: Study population characteristics.

"Role-Physical" and "Vitality".

Table 6 shows that the over 60 age group of our study has higher scores in the majority of aspects when compared to people of the same age in the general population. However, lower scores can be observed in "Bodily Pain" and "Social Functioning".

\section{Discussion}

Type 2 diabetes mellitus is a chronic disease, which indisputably affects the quality of life of those who suffer from it. The impact produced by this disease is largely influenced by conduct, beliefs and knowledge about chronic illness. Quality of life is a complex concept comprised of various aspects, which are difficult to define. The patient expresses his/ her own perception of well-being or satisfaction subjectively in relation to objective aspects linked to physical, mental and social health $[3,4]$.

Our research demonstrates that the disease as has been shown in prior studies6-8 negatively affects the self-perceived health-related quality of life (HRQOL) of type 2 diabetics, in relation to the general population. This alteration of HRQOL has been researched in different diabetic populations $[13,14]$ with special emphasis on the presence of complications [15-17].

The scores for the majority of aspects in the SF-36 survey is lower in our diabetic population study than the one described for the Spanish general population by López [7] and other studies carried out on the Andalusian population [17]. We have also observed that the average score for the majority of the survey's aspects is lower than the one

\begin{tabular}{|c|c|c|c|c|c|c|c|c|}
\hline & $\begin{array}{c}\text { Physical } \\
\text { Functioning }\end{array}$ & Role-Physical & Bodily Pain & General Health & Vitality & $\begin{array}{c}\text { Social } \\
\text { Functioning }\end{array}$ & Role-Emotional & Mental Health \\
\hline $\mathrm{n}$ & 148 & 148 & 148 & 148 & 148 & 148 & 148 & 148 \\
\hline Average & 75.5 & 87.8 & 48.5 & 68.1 & 62.3 & 57.3 & 84.7 & 66.9 \\
\hline Median & 76.7 & 100 & 54.5 & 68 & 58.3 & 60 & 100 & 70 \\
\hline $\begin{array}{l}\text { Standard } \\
\text { deviation }\end{array}$ & 15.2 & 19.6 & 20.4 & 7.1 & 12 & 10.7 & 20.9 & 7.6 \\
\hline Minimum & 50 & 50 & 18.2 & 56 & 41.7 & 30 & 50 & 53.3 \\
\hline Maximum & 100 & 100 & 81.8 & 84 & 87.5 & 90 & 116.7 & 76.7 \\
\hline Percentile 25 & 63.3 & 75 & 36.4 & 64 & 58.3 & 50 & 66.7 & 60.0 \\
\hline Percentile 75 & 8.7 & 100 & 63.6 & 72 & 69.8 & 60 & 100 & 73.3 \\
\hline
\end{tabular}

Table 2: Results of aspects studied in the SF-36 survey.

\begin{tabular}{|c|c|c|c|c|}
\hline & \multicolumn{2}{|c|}{ Population DM-2 Serón } & \multicolumn{2}{|c|}{ General population } \\
\hline & Average & Standard deviation & Average & Standard deviation \\
\hline Physical Functioning & 75.2 & 15.2 & 84.7 & 24 \\
\hline Role-Physical & 87.8 & 19.5 & 83.2 & 35.2 \\
\hline Bodily Pain & 48.4 & 20.3 & 79 & 22.3 \\
\hline General Health & 68 & 7.1 & 68.3 & 22.3 \\
\hline Vitality & 62.3 & 12 & 66.9 & 22.1 \\
\hline Social Functioning & 57.2 & 10.7 & 90.1 & 20 \\
\hline Role-Emotional & 84.6 & 20.8 & 88.6 & 30.1 \\
\hline Mental Health & 66.8 & 7.6 & 73.3 & 20.1 \\
\hline
\end{tabular}

Table 3: Comparison between general population and population with DM2 Clinical Management Unit, Serón. 


\begin{tabular}{|c|c|c|c|c|c|}
\hline & Sex & $\mathbf{N}$ & Average & $\begin{array}{l}\text { Standard } \\
\text { deviation }\end{array}$ & Significance \\
\hline \multirow{2}{*}{ Physical Functioning } & Men & 71 & 80.0 & 15.6 & \multirow{2}{*}{0.001} \\
\hline & Women & 77 & 71.5 & 13.8 & \\
\hline \multirow{2}{*}{ Role-Physical } & Men & 71 & 90.5 & 18.6 & \multirow{2}{*}{0.113} \\
\hline & Women & 77 & 85.4 & 20.2 & \\
\hline \multirow{2}{*}{ Bodily Pain } & Men & 71 & 41.4 & 21.9 & \multirow{2}{*}{0.000} \\
\hline & Women & 77 & 55.0 & 16.5 & \\
\hline \multirow{2}{*}{ General Health } & Men & 71 & 69.0 & 7.0 & \multirow{2}{*}{0.138} \\
\hline & Women & 77 & 67.2 & 7.2 & \\
\hline \multirow{2}{*}{ Vitality } & Men & 71 & 60.7 & 8.0 & \multirow{2}{*}{0.120} \\
\hline & Women & 77 & 63.8 & 14.7 & \\
\hline \multirow{2}{*}{ Social Functioning } & Men & 71 & 52.7 & 9.4 & \multirow{2}{*}{0.000} \\
\hline & Women & 77 & 61.6 & 10.1 & \\
\hline \multirow{2}{*}{ Role-Emotional } & Men & 71 & 89.0 & 17.4 & \multirow{2}{*}{0.016} \\
\hline & Women & 77 & 80.7 & 23.1 & \\
\hline \multirow{2}{*}{ Mental Health } & Men & 71 & 68.9 & 6.4 & \multirow{2}{*}{0.002} \\
\hline & Women & 77 & 65.0 & 8.2 & \\
\hline
\end{tabular}

Table 4: Averages and $t$-test of different aspects depending on gender in DM2 Clinical Managment Unit, Serón.

\begin{tabular}{|c|c|c|c|c|c|}
\hline & Age group & $\mathbf{N}$ & Average & $\begin{array}{l}\text { Standard } \\
\text { deviation }\end{array}$ & Significance \\
\hline \multirow{2}{*}{ Physical Functioning } & Under 60 & 38 & 78.3 & 19.1 & \multirow{2}{*}{0.205} \\
\hline & Over 60 & 110 & 74.6 & 13.6 & \\
\hline \multirow{2}{*}{ Role-Physical } & Under 60 & 38 & 81.6 & 22.1 & \multirow{2}{*}{0.022} \\
\hline & Over 60 & 110 & 90.0 & 18.2 & \\
\hline \multirow{2}{*}{ Bodily Pain } & Under 60 & 38 & 38.5 & 20.8 & \multirow{2}{*}{0.000} \\
\hline & Over 60 & 110 & 51.9 & 19.1 & \\
\hline \multirow{2}{*}{ General Health } & Under 60 & 38 & 69.1 & 4.3 & \multirow{2}{*}{0.317} \\
\hline & Over 60 & 110 & 67.7 & 7.8 & \\
\hline \multirow{2}{*}{ Vitality } & Under 60 & 38 & 58.5 & 9.0 & \multirow{2}{*}{0.024} \\
\hline & Over 60 & 110 & 63.6 & 12.7 & \\
\hline \multirow{2}{*}{ Social Functioning } & Under 60 & 38 & 58.7 & 7.0 & \multirow{2}{*}{0.352} \\
\hline & Over 60 & 110 & 56.8 & 11.7 & \\
\hline \multirow{2}{*}{ Role-Emotional } & Under 60 & 38 & 81.6 & 19.3 & \multirow{2}{*}{0.289} \\
\hline & Over 60 & 110 & 85.8 & 21.4 & \\
\hline \multirow{2}{*}{ Mental Health } & Under 60 & 38 & 68.6 & 7.6 & \multirow{2}{*}{0.109} \\
\hline & Over 60 & 110 & 66.3 & 7.6 & \\
\hline
\end{tabular}

Table 5: Averages and $t$-test of different aspects depending on age group in DM2 Clinical Management Unit, Serón.

\begin{tabular}{|c|c|c|c|c|}
\hline & \multicolumn{2}{|c|}{ Population DM2 $\mathbf{6 0}$ years } & \multicolumn{2}{|c|}{$\begin{array}{c}\text { General population >60 } \\
\text { years }\end{array}$} \\
\hline & Average & $\begin{array}{l}\text { Standard } \\
\text { deviation }\end{array}$ & Average & $\begin{array}{c}\text { Standard } \\
\text { deviation }\end{array}$ \\
\hline Physical Functioning & 74.6 & 13.6 & 65.7 & 29.8 \\
\hline Role-Physical & 90.0 & 18.2 & 73.3 & 41.1 \\
\hline Bodily Pain & 51.9 & 19.1 & 68.4 & 29.9 \\
\hline General Health & 67.7 & 7.8 & 55.9 & 21.5 \\
\hline Vitality & 63.6 & 12.7 & 60.5 & 24.7 \\
\hline Social Functioning & 56.8 & 11.7 & 79.2 & 28 \\
\hline Role-Emotional & 85.8 & 21.4 & 84.8 & 32.8 \\
\hline Mental Health & 66.3 & 7.6 & 68.3 & 22.3 \\
\hline
\end{tabular}

Table 6: Comparison results of general population $>60$ and DM2 population Clinical Management Unit, Serón $>60$ years.

described by Hervás for a diabetic population in a basic health area in the Autonomous Community of Navarra [12]. However, it should be noted that higher scores were obtained for "Role-Physical" and "General Health" than in Navarra.
The lowest average obtained by our population was in "Bodily Pain" and "Social Functioning"; these results are similar to other studies in which a decrease in social activity is perceived by patients with type 2 diabetes mellitus $[18,19]$. It is possible that these results are due to the elevated average age of our population (71.3 years) and a prolonged time of evolution of the disease. The "Social Functioning" aspect is negatively correlated to men, as these patients perceive difficulties in carrying social activities and relationships.

However, the score for "Role-Physical" was higher in our population than in the general population, with similar results to those obtained by the Hortega study [20]. The study population lives in a rural area in the region of Valle del Almanzora (Almeria). Small scale agricultural activity is a usual source of livelihood, source of extra income or leisure. The retired population in this area carry out these types of tasks as a way of keeping physically active. This may be the reason for our patient's higher perception of well-being in this aspect when compared to the general population as described by López [7].

Quality of life is negatively correlated to women in the majority of aspects of the survey. We found statistically significant differences for "Physical Functioning", "Role-Emotional" and "Mental Health". However, there is a positive correlation to women for "Bodily Pain", and "Social Functioning", these being the differences between men and women with high statistical significance $(p<0.001)$. "Bodily Function" is the most affected aspect in our study population. The perception of physical discomfort and tiredness is higher in diabetic women than in diabetic men. Similar results have been obtained in other studies [21] that discovered that a third of the sample of diabetic patients had intense pain that interfered in their daily work. This can be due to diabetes mellitus being a disease, which affects circulation and peripheral innervation causing damage mainly to the free nerve endings of distal parts of the body. These alterations are responsible for somatosensitive complications such as pain and paresthesia [22]. Prior research indicates that diabetic patients who participate less in social activities, which is the profile of the patients in our study, tend to neglect their treatment $[23,24]$. This is why we believe that sex and social aspects linked to gender must be studied in depth using qualitative methods, which will help uncover aspects of quality of life of patients with type 2 diabetes mellitus.

In the majority of aspects in the survey used in our study, healthrelated quality of life is also negatively correlated to age. Patients aged over 60 scored less than those under that age. "Bodily Pain" still presents the highest statistical significance negatively correlated to diabetics aged over 60 . Our results are in accordance with other studies carried out on diabetic patients $[12,17]$. Other research has indicated that patients with chronic pathologies self-perceive that their health-related quality of life decreases with age [25-27]. In contrast, when we compare the over 60 age group in our study with the general population of the same age the scoring of the diabetic patients is higher in most aspects. Similar results were observed in Hervas's study [12], while our research indicated higher scores than those presented by Coronado et al. [17].

\section{Conclusion}

This research investigation increases the evidence that type 2 diabetes mellitus is linked to a poorer perception of health-related quality of life (HRQOL). Diabetic patients perceive poorer quality of life than the rest of the population. HRQOL is especially affected in female diabetic patients. Diabetic patients also perceive a decrease in satisfaction with their state of health as they get older. However, the 
over 60 age group perceived themselves to be as healthy as people of their same age who are not diabetic.

Therefore, it must be highlighted that the impact that certain diseases have on patients cannot be measured solely by the quantification of objective clinical parameters (like morbidity and mortality). It must also be noted that in the assessment of the diabetic population psychosocial aspects must be taken into account to improve self-monitoring and treatment maintenance in addition to clinical and analytical factors. We recommend that future studies on type 2 diabetes include surveys that measure HRQOL in combination with qualitative studies in order to obtain a more precise assessment of the values and beliefs that diabetic patients associate with self-monitoring of their disease.

\section{Conflict of Interest}

The main researchers affirm that they have no conflict of interest in relation to the research investigation described in this report.

\section{References}

1. Franch Nadal J, Alvarez Torices JC, Alvarez Guisasola F, Diego Domínguez F, Hernández Mejía R, et al. (1992) Epidemiology of diabetes mellitus in the province of Leon. Med Clin (Barc) 98: 607-611.

2. Rodríguez B, Sanchis C, García F, Divison JA, Artigao LM, et al. (2000) Prevalencia de la diabetes mellitus y su relación con otros factores de riesgo cardiovascular en la provincia de Albacete. Grupo de Enfermedad Vascular en Albacete (GEVA). Atención Primaria 2000; 25: 166-171.

3. de Salud C (2002) Proceso Asistencial Integrado Diabetes Mellitus tipo 2 Consejería de Salud. Junta de Andalucía. Sevilla.

4. Badía X, Salamero M, Alonso J. Medidas genéricas de la Calidad de Vida Relacionada con la Salud (1999) En: Badía X, Salamero M, Alonso J. La medida de la salud. Guía de escalas de medición en español. Barcelona: Edimac ediciones, 105-174.

5. Badía X, Lizan L. Estudios de Calidad de Vida (2003) En: Martín Zurro A Cano Pérez FJ, editors. Atención Primaria. Conceptos, organización y práctica clínica. Madrid: Elsevier España ediciones, 250-261.

6. Aguilar Diosdado M, Amo Alfonso M, Lama Herrera C, Mayoral Sánchez $E$ (2009) II Plan Integral de Diabetes de Andalucía: 2009-2013.

7. Alonso J, Regidor E, Barrio G, Prieto L, Rodríguez C, et al. (1998) Population reference values of the Spanish version of the Health Questionnaire SF-36. Med Clin (Barc) 111: 410-416.

8. Newnham EA, Harwood KE, Page AC (2007) Evaluating the clinical significance of responses by psychiatric inpatients to the mental health subscales of the SF36. J Affect Disord 98: 91-97.

9. López-García E, Banegas JR, Graciani Pérez-Regadera A, Gutiérrez-Fisac $\mathrm{JL}$, Alonso J, et al. (2003) Population-based reference values for the Spanish version of the SF-36 Health Survey in the elderly. Med Clin (Barc) 120: 568573.

10. Senez B, Felicioli P, Moreau A, Le Goaziou MF (2004) Quality of life assessment of type 2 diabetic patients in general medicine. Presse Med 33: 161-166.

11. Mena Martín FJ, Martín Escudero JC, Simal Blanco F, Bellido Casado J, Carretero Ares JL (2006) Type 2 diabetes mellitus and health-related quality of life: results from the Hortega Study. An Med Interna 23: 357-360.
12. Hervás A, Zabaleta A, De Miguel G, Beldarráin O, Díez J (2007) Health related quality of life in patients with diabetes mellitus type 2. An Sist Sanit Navar 30: 45-52.

13. Wändell PE (2005) Quality of life of patients with diabetes mellitus. An overview of research in primary health care in the Nordic countries. Scand J Prim Health Care 23: 68-74.

14. Paschalides C, Wearden AJ, Dunkerley R, Bundy C, Davies R, et al. (2004) The associations of anxiety, depression and personal illness representations with glycaemic control and health-related quality of life in patients with type 2 diabetes mellitus. J Psychosom Res 57: 557-564.

15. Johnson JA, Nowatzki TE, Coons SJ (1996) Health-related quality of life of diabetic Pima Indians. Med Care 34: 97-102.

16. De Berardis G, Franciosi M, Belfiglio M, Di Nardo B, Greenfield S, et al. (2002) Quality of Care and Outcomes in Type 2 Diabetes (QuED) Study Group. Erectile dysfunction and quality of life in type 2 diabetic patients: a serious problem too often overlooked. Diabetes Care 25: 284-291.

17. Vázquez VC, González LM, Ruiz EM, Isidoro JM, Ordóñez MS, et al. (2011) Assessment of health outcomes in the type 2 diabetes process. Aten Primaria 43: $127-133$

18. Stewart AL, Greenfield S, Hays RD, Wells K, Rogers WH, et al. (1989) Functional status and well-being of patients with chronic conditions. Results from the Medical Outcomes Study. JAMA 262: 907-13.

19. Hänninen J, Takala J, Keinänen-Kiukaanniemi S (1998) Quality of life in NIDDM patients assessed with the SF-20 questionnaire. Diabetes Res Clin Pract 42: 17-27.

20. Mena Martín FJ, Martín Escudero JC, Simal Blanco F, Bellido Casado J Carretero Ares JL (2006) Type 2 diabetes mellitus and health-related quality of life: results from the Hortega Study. An Med Interna 23: 357-360.

21. Vinaccia S, Fernández H, Escobar O, Calle E, Andrade IC, et al. (2006) Calidad de vida y conducta de enfermedad en pacientes con diabetes Mellitus tipo II. Suma Psicologica 13: 15-31.

22. Contreras F, Esguerra G, Espinosa J, Gutiérrez C, Fajardo L, et al. (2006) Calidad de vida y adhesión al tratamiento en pacientes con insuficiencia renal crónica en tratamiento de hemodiálisis. Universitas Psychologica 5: 487-499.

23. Walker R, Rodgers (2006) J. Diabetes: manual práctico para el cuidado de su salud. Buenos Aires: Blume Ediciones.

24. Väätäinen S, Keinänen-Kiukaanniemi S, Saramies J, Uusitalo H, Tuomilehto J et al. (2014) Quality of life along the diabetes continuum: a cross-sectional view of health-related quality of life and general health status in middle-aged and older Finns. Quality of Life Research 23: 1935-1944.

25. Alonso J, Prieto L, Antó JM (1995) [The Spanish version of the SF-36 Health Survey (the SF-36 health questionnaire): an instrument for measuring clinical results]. Med Clin (Barc) 104: 771-776.

26. Espinosa De Los Monteros MJ, Alonso J, Ancochea J, González A (2002) Quality of life in asthma: reliability and validity of the short form generic questionnaire (SF-36) applied to the population of asthmatics in a public health area. Arch Bronconeumol 38: 4-9.

27. Ambriz Y, Menor R, Campos-González I D y Cardiel M H (2015) Calidad de vida relacionada con la salud en artritis reumatoide, osteoartritis, diabetes mellitus, insuficiencia renal terminal y población geriátrica. Experiencia de un Hospital General en México. Reumatología Clínica 11: 68-72. 